\title{
Diester-containing Zwitterionic Gemini Surfactants with Different Spacer and Its Impact on Micellization Properties and Viscosity of Aqueous Micellar Solution
}

\author{
Sachin Vasant Patil, Sanyukta Arun Patil and Amit Prabhakar Pratap* \\ Department of Oils, Oleochemicals and Surfactants Technology, Institute of Chemical Technology (University under Section 3 of UGC Act 1956; \\ Formerly UDCT/ UICT), Nathalal Parekh Road, Matunga (East), Mumbai-400 019, INDIA
}

\begin{abstract}
A series of diester containing zwitterionic gemini surfactants, $N, N$-dimethyl- $N$-alkyl-2-[[hydroxy (alkoxy) phosphinyl]oxy]-alkylammonium designated as $\mathrm{C8}(-)-\mathrm{S}-\mathrm{Cn}(+), \mathrm{S}=2$ and $3, \mathrm{n}=12,14$ and 16, were synthesized and characterized by instrumental techniques namely FT-IR, ${ }^{1} \mathrm{H}$ NMR, ${ }^{13} \mathrm{C}$ NMR, ${ }^{31} \mathrm{P}$ NMR and Mass spectral studies. These new gemini surfactants further investigated for their various surfactant properties. The critical micelle concentration $(\mathrm{cmc})$ and the effectiveness of surface tension reduction $\left(\Pi_{\mathrm{cmc}}\right)$ were determined as a function of surfactant concentration by means of surface tension measurement. Micellization and viscosity properties were investigated by surface tension, electrical conductivity, dye micellization and rheology techniques. The findings of the aqueous surfactant system obtained were impacted by polarity, size and the nature of zwitterions as the surface. The thermodynamic and viscosity properties of these surfactants found to be based on the structures of gemini surfactants.
\end{abstract}

Key words: gemini surfactants, zwitterionic, critical micelle concentration, conductivity, dye micellization, rheology

\section{INTRODUCTION}

Zwitterionic gemini surfactants are result of a product concept, production of surfactants based on oleochemicals on a commercial scale is relatively new. According to the national or international standards, looking for biodegradable $^{1-3)}$, low cost and high-yield routes for the production of renewable sources derived surfactants ${ }^{4,5)}$ is current. Gemini surfactants are a group of surfactant molecules consisting of two hydrophobic tail and two hydrophilic headgroups connected through a spacer entity; which may be rigid or flexible ${ }^{6,7)}$. These types of surfactants are considered interesting in many respectes to their monomeric surfactants due to their superior aqueous properties which are figured on the nature and size of the spacer and hydrophobic groups ${ }^{8,9)}$.

Most commonly, they are classified into four categories according to polar head groups i.e. anionic, cationic, nonionic and zwitterionic. Among them, zwitterionic surfactants, which are electrically neutral, therefore, counterions free because of the proximity of two headgroups; one negatively charged phosphodiester anion and one positively charged ammonium cation connected by spacer. Likewise amino acids; they exist in the form of inner salts. Diglycer- ides and phospholipids are usually asymmetrical if they are branched or double tailed and the best-known examples of naturally found zwitterions ${ }^{10-12)}$. Many researchers have contributed themselves on the study of asymmetrical structure-property relationships of surfactants at various interfaces ${ }^{13)}$.

Based on this background, we have investigated the gemini surfactants with different types of head group surfactants as "heterogeminis" ${ }^{14)}$. Since the synthesis of this type of different structural geometry are now being widely investigated as they are considered as potential surfactant molecule. The length of the two hydrocarbon tails, one of which is attached to the phosphate group is branched and of 8 carbon atoms and other is attached to the quaternary ammonium group varying between 12 to 16 carbon atoms. As expected, its unique structures allows for the design of the wide variety of gemini surfactants. Jaeger et al. in 1996 gives the first report on anionic and cationic headgroups based zwitterionic geminis ${ }^{15)}$. This ideas was followed by Menger in 1999, 2001-2003, who synthesized a great variety of anionic-cationic headgroups gemini surfactants ${ }^{16,22-24)}$. Afterwards another report on anionic-nonionic ${ }^{17,18)}$ and nonionic-nonionic ${ }^{14)}$ have been illustrated. The potential of

\footnotetext{
*Correspondence to: Amit Prabhakar Pratap, Department of Oils, Oleochemicals and Surfactants Technology, Institute of Chemical Technology (University under Section 3 of UGC Act 1956; Formerly UDCT/ UICT), Nathalal Parekh Road, Matunga (East), Mumbai-400 019, INDIA E-mail: amitpratap2001@gmail.com Accepted April 30, 2016 (received for review December 30, 2015)
} Journal of Oleo Science ISSN 1345-8957 print / ISSN 1347-3352 online http://www.jstage.jst.go.jp/browse/jos/ http://mc.manusriptcentral.com/jjocs 
structure variability is simply enormous for zwitterionic gemini surfactants. These surfactants demonstrate lower critical micelle concentrations and surface tension, which are attributed to their structural variety.

In this paper, we report the synthesis and surface active properties of di-ester containing zwitterionic gemini surfactants, $N, N$-dimethyl- $N$-alkyl-2[[hydroxy (alkoxy) phosphinyl] oxy]-alkylammonium, with different spacer labeled to as $\mathrm{C} 8(-)-\mathrm{S}-\mathrm{Cn}(+), \mathrm{S}=2$ and $3, \mathrm{n}=12,14$ and 16 . The critical micelle concentration (cmc) and the effectiveness of surface tension reduction $\left(\Pi_{\mathrm{cmc}}\right)$ were determined as a function of surfactant concentration by means of surface tension measurement as evident by Wilhelmy plate technique and micellization properties were also investigated by electrical conductivity and dye micellization. The basic focus of this work is to study the branching effect of hydrophobic tail attached to the phosphate group with the influence of spacer on the thermodynamic and viscosity properties of gemini surfactants.

\section{EXPERIMENTAL SECTION}

\subsection{Materials and methods}

Phosphoryl trichloride, triethylamine (dry), ethane-1,2diol, propane-1,2-diol, benzene (dry), 2-ethylhexan-1-ol, 2-propanol and all chemicals used in this study were of analytical reagent grade, procured from S. D. Fine Chemicals Limited, India and used without any further purification. 1(Dimethylamino) dodecane ( $\geq 95 \%)$ was obtained from Acros Organics, 1-(Dimethylamino) tetradecane ( $\geq 95 \%)$, 1- (Dimethylamino) hexadecane ( $\geq 95 \%)$ were received from Sigma-Aldrich and used as received. Eosin-Y dye and standard $\mathrm{KCl}$ solutions were obtained from Thomas baker (chemicals) Pvt. Ltd, India. All of the surfactant solutions were prepared with ultrapure water produced by the Millipore Q3 system with a resistivity above $1.82 \times 105 \Omega \cdot \mathrm{m}$ and the measurements were performed at $25 \pm 1^{\circ} \mathrm{C}$.

\subsection{Synthesis}

The zwitterionic gemini surfactants, referred to as C8(-) -S-Cn $(+)$ throughout the work, were prepared according to the previous procedures, shown in Fig. 1, illustrated by Lucas et al. in 1950 and Edmundson et al. in $1962^{20,21)}$. This work was followed by Menger et al. in 2001-2003 ${ }^{22-24)}$. The synthesis was carried out in two steps as illustrated in scheme, the first step involves the synthesis of 2-(alkoxy) -2-oxo-1,3,2-dioxaphospholane and 2-(alkoxy)-2-oxo4-methyl-1,3,2-dioxaphospholane (cyclic alkyl phosphodiester) and in the second step, quaternization of cyclic alkyl phosphodiester to obtain desired gemini surfactants.

Step 1

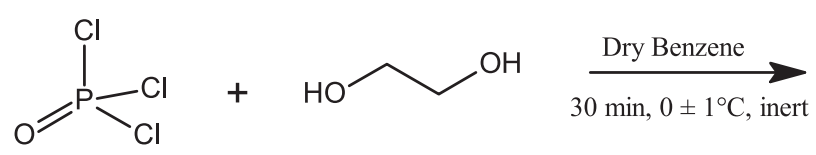<smiles>O=P1(Cl)OCCO1</smiles>

(1)

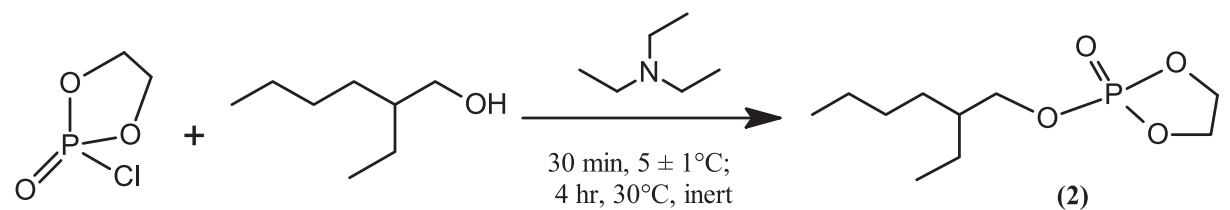

Step 2<smiles>CCCCCCCCCCCC[N+](C)(C)CCOP(=O)([O-])OCC(CC)CCCC</smiles>

Fig. 1 The general route for synthesis of zwitterionic gemini surfactants, C8(-)-2-C12(+), N, N-dimethyl- $N$-ethyl-2[[hydroxy (2-Ethylhexyloxy) phosphinyl] oxy]-dodecanammonium. 


\subsection{Tensiometric measurements}

The equilibrium surface tension of surfactant solutions at an air-liquid interface were performed by Krüss tensiometer Model K100 MK2 as evidence by standard Wilhelmy platinum plate. Due to the adsorption of the surfactant on the surface of the plate, there was a fluctuation in reading measurements. To avoid this, the surface was cleaned properly after each measurement. The platinum plate surface was washed first with pure water, acetone, and burned to red hot under flame to remove the adsorbed surfactants completely. The temperature was maintained throughout the measurements within $25 \pm 0.01^{\circ} \mathrm{C}$ by a digital thermostated bath. The cmc values were determined by noting distinct breaks from equilibrium surface tension $(\gamma)$ as a function of the logarithm of concentration $(\log C)$ plots for zwitterionic gemini surfactants in a aqueous solution at $25^{\circ} \mathrm{C}$.

The several adsorption physicochemical parameters were determined from the $\gamma$ vs. Log $\mathrm{C}$ plots. The maximum surface excess concentration $\left(\Gamma_{\max }\right)$ at air/water interface has been determined from Gibbs adsorption isotherm which was calculated from the slope of the $\gamma v s$. Log $\mathrm{C}$ plots when the concentration is reached plateau region. Minimum area per molecule $\left(\mathrm{a}_{\min }\right)$ was calculated by influence of $\Gamma_{\max }$ and Avogadro's number. The $\Pi_{\mathrm{cmc}}$ denotes the effectiveness of surface tension (surface pressure) and calculated by difference between the surface tension of pure water and the surfactant solution at cmc. The $\mathrm{pC}_{20}$ values were calculated from the negative logarithm of the surfactant concentration required to reduce the surface tension of pure water by $20 \mathrm{mN} / \mathrm{m}$. The Gibbs free energy of micellization $\left(\Delta G_{\text {mic }}^{\circ}\right)$ and adsorption $\left(\Delta G_{\text {ads }}^{\circ}\right)$ was calculated from the cmc and $\Gamma_{\max }$ values; substituted in equations described in results and discussion.

\subsection{Conductivity measurements}

The conductivity measurements were carried out in the form of titrations by adding concentrated stock solution of surfactants in pure water over the whole mole fraction range, keeping the total surfactant concentration at least 10 times higher than the cmc of each component. The conductivity measurements were performed using a directreading Eutech Instruments conductivity meter (Model PC 510) equipped with a dip cell (cell constant $=1 \mathrm{~cm}^{-1}$ ). The conductivity cell was calibrated with standard $\mathrm{KCl}$ solutions. The cmc values were determined as a function of surfactants concentration by means of specific conductivity. These cmc graphs were useful in determine the self-aggregation and thermodynamic parameters for these di-ester based surfactants. The degree of counterion binding $(\beta)$ was calculated from the degree of ionization $(\alpha)$; which is determined from the ratio of the slope above and below the indicative of cmc value.

\subsection{Dye micellization}

The double beam UV-Visible spectrophotometer (Shimadzu-UV 1800 series) was used to record the ultraviolet visible spectrums and absorbance with matched pair of cuvettes of $1 \mathrm{~cm}$ optical path length. The interaction of dye was studied by anionic Eosin-Y dye (EY) and the synthesized zwitterionic gemini surfactants. The EY dye shows shift in absorbance due to the presence of micelles. Plot of surfactant concentration versus the absorbance, at wavelength $(\lambda \max ) 517 \mathrm{~nm}$ and fixed dye concentration $\left(1 \times 10^{-6}\right.$ $\mathrm{mol} / \mathrm{L}$ ) was used to study the micellization and binding of synthesized gemini surfactants.

\subsection{Qualitative determination of quaternary ammonium salt}

The surfactant solution(1\%) of about $5 \mathrm{~mL}$ was taken in a test tube. $0.1 \mathrm{~N}$ sodium hydroxide solution was added to it to turn the solution basic. $5 \mathrm{~mL}$ Chloroform was added to the solution, then bromophenol blue indicator $(0.5 \%$ in ethanol: water; 2:3) was added per drops to the mixture. The mixture was shaken and two layers formed were separated from one another. The organic layer became blue, which indicated the existence of quaternary ammonium salt $^{19)}$.

\subsection{Differential scanning calorimetry}

The melting temperature ( $\mathrm{Tm}$ ) of the newly synthesized zwitterionic gemini surfactants were studied using a differential scanning calorimeter (DSCQ100 analyzer, T.A. Instrument, USA) at a heating rate of $10^{\circ} \mathrm{C} / \mathrm{min}$ and a temperature of $40-250^{\circ} \mathrm{C}$.

\subsection{Rheology measurements}

The stress-controlled rotational rheometer, MCR 301 (Anton Paar) equipped with cone-plate geometries (CP-502 ) of $50 \mathrm{~mm}$ diameter with $2^{\circ}$ cone angle was used to perform viscosity measurements of the aqueous surfactant solutions at $25^{\circ} \mathrm{C}$. The aqueous solutions of surfactants were equilibrated at $25^{\circ} \mathrm{C}$ before measurements for $1 \mathrm{~h}$. The steady shear rate measurement gives the determined values of zero shear viscosity of the samples by viscosity generalization in shear rate curve to zero shear rate obtained from rheological measurements.

\section{RESULTS AND DISCUSSION}

\subsection{Synthesis and Characterizations}

In the ring opening reaction, the $2 \mathrm{EhOP}$ and $2 \mathrm{EhOmP}$ was reacted with 1-(Dimethylamino) dodecane or 1-(Dimethylamino) tetradecane or 1-(Dimethylamino) hexadecane to give the respective zwitterionic gemini amphiphiles as shown in Fig. 2 (a). In the present work modified procedures was followed, that the COP was prepared in benzene 


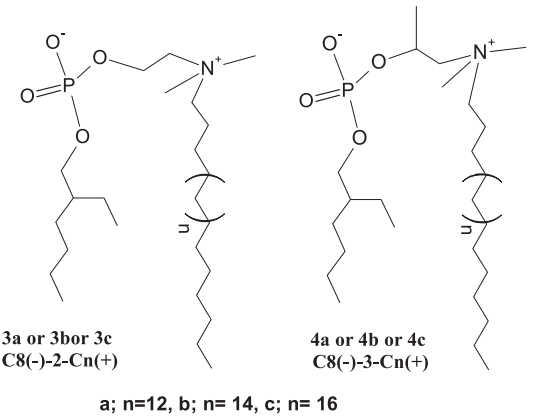

(a)

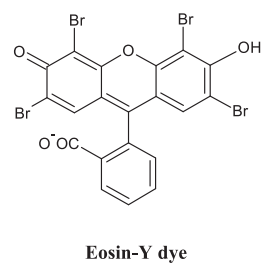

(b)
Fig. 2 Structures of two series of zwitterionic gemini surfactants (a) and structure of anionic Eosin-Y dye (b).

and the last step of reaction was carried out in 2-propanol instead of the solvent as illustrated in procedure by Menger et $a l$.. The second step as shown in Fig. 1, quaternization reaction of $2 \mathrm{EhOP}$ and $2 \mathrm{EhOmP}$ with tertiary amine is a SN2 reaction in which the reaction solvent 2-propanol plays a remarkable role of good polarity and solubility of intermediate $^{25)}$. The yield of COmP would be lower if proper precautions were not taken and prepared according to the method described above. For COP, yield was only $84 \%$ possibly because of there was an excess of one reactant and when the reaction mixture was allowed to stand overnight and also make late in solvent removal was moreover critical, lower the yield by 20-30\%. If there was in all these cases, large residue formed. The residue was relatively viscous, yellowish liquid from which a small amount of acute yellow coloured precipitate settled out after $24 \mathrm{~h}$. The solid mass was removed by vacuum filtration system placed with Buchner funnel. The formation of geminis was confirmed by the qualitative determination as described in methods and they were shown the organic layer became blue, which indicated the existence of quaternary ammonium salt indicates the formation of geminis.

A FT-IR Shimadzu Model IRAffinity-1, Japan(ATR)was used to identify the functionality of zwitterionic gemini surfactants C8 (-) -S-Cn $(+)$. Figure $3(\mathbf{A})$ and $(\mathbf{B})$ depicted that the FT-IR spectra of six different types of zwitterionic gemini amphiphiles were very similar. The IR spectra of
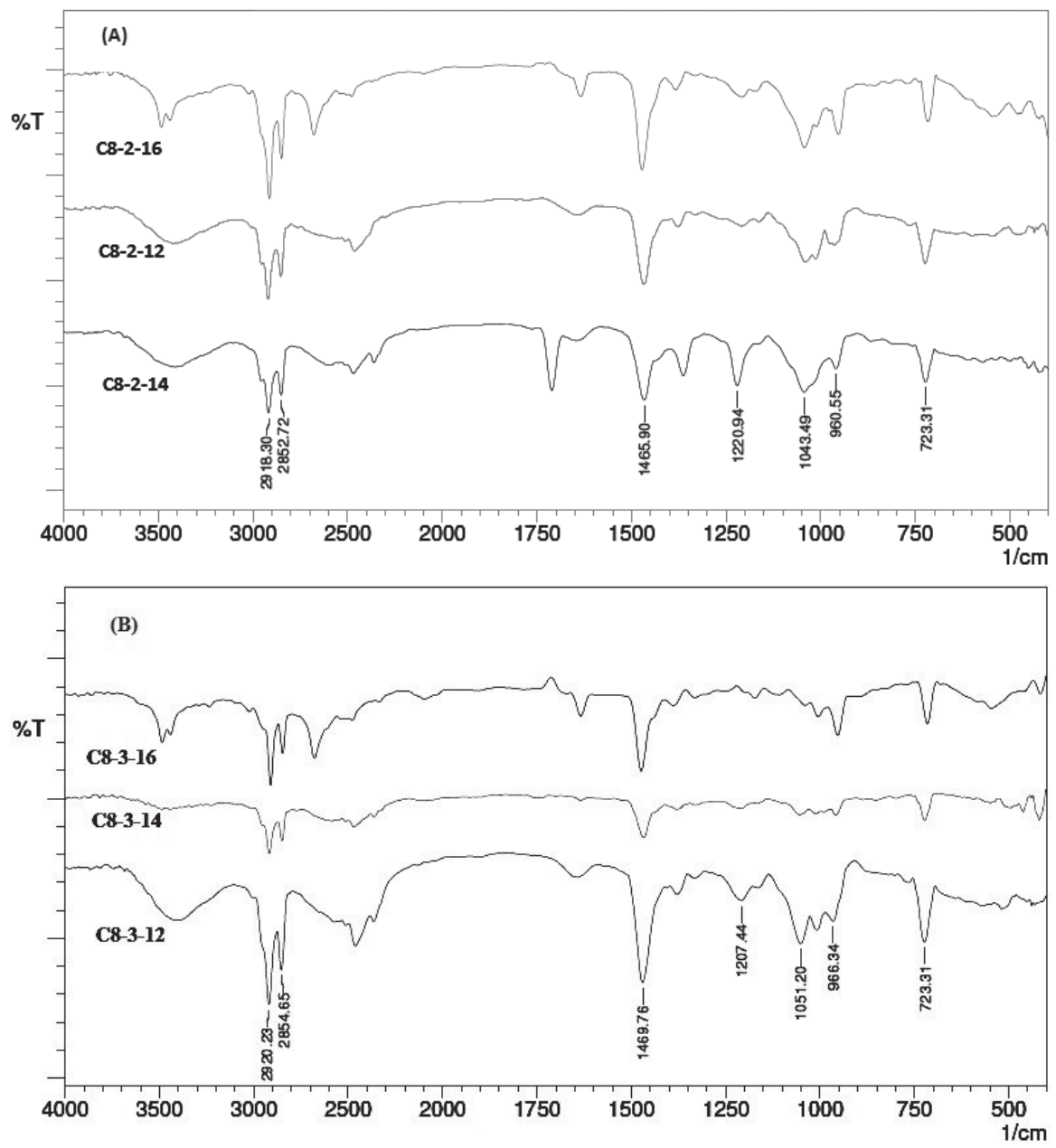

Fig. 3 FT-IR spectra of zwitterionic gemini surfactants C8(-)-2-Cn(+); (A), C8(-)-3-Cn(+); (B); where n=12, 14 and 16. 
these gemini amphiphiles exhibited the phosphonyl stretch $\mathrm{P}=\mathrm{O}$ of ester in the range of $1241-1220 \mathrm{~cm}^{-1}$. The bands of C-O stretching had been observed at the range of 1051$1044 \mathrm{~cm}^{-1}$. As shown in Fig. 3, in the range of 1368-1350 $\mathrm{cm}^{-1}$ showed stretching frequency for the directly attached carbon to the cationic nitrogen which indicates that the formation of desired geminis.

The chemical structures of zwitterionic gemini surfactants and cyclic phosphodiester has been further investigated by ${ }^{1} \mathrm{H}$ NMR, ${ }^{13} \mathrm{C}$ NMR and ${ }^{31} \mathrm{P}$ NMR studies. The ${ }^{1} \mathrm{H}$ NMR spectra of cyclic phosphodiester and the surfactants are shown in Supporting Information. The chemical shifts for spacer unit protons in the functionality between diester group was observed as a singlet at $\delta 3.97$ and $4.01 \mathrm{ppm}$ for zwitterionic gemini surfactants $\mathrm{C} 8(+)-2-\mathrm{C} 14(+)$ and C8 $(+)-3-C 16(+)$ respectively. The characteristic resonance signal obtained between $\delta 3.08-2.83$ ppm could be attributed to protons directly attached to cationic nitrogen which are part of hydrophobic tail for the zwitterionic geminis. The signals obtained as a multiplet between $\delta$ 3.41-3.29 ppm corresponded to the respective adjacent quaternary carbon. The terminal methyl protons in both hydrophobic tails were confirmed by a peak triplet at $\delta 0.9$ ppm. The sharp signals obtained as multiplet in-between $\delta$ 1.36 - 1.19 ppm could be attributed to the methylene protons of aliphatic chains for zwitterionic gemini surfactants. The characteristic resonance signal for proton at branched aliphatic chain, which is part of anionic phosphate group, was observed between $\delta 1.77-1.62$ ppm for gemini surfactants. The characteristic resonance signal for the phosphorous peak of $\mathrm{C} 8(+)-2-\mathrm{C} 16(+)$ and $\mathrm{C} 8(+)$ $-3-\mathrm{C} 16(+)$ appeared as sharp and symmetric peak at $\delta-$ 0.420 and -0.554 respectively which were confirms the purity of products.

The ${ }^{13} \mathrm{C}$ NMR spectra of $\mathrm{C} 8(+)-2-\mathrm{C} 16(+)$ and $\mathrm{C} 8(+)$ -3-C16 $(+)$ gemini surfactants are shown in Supporting Information as representative spectra. The ${ }^{13} \mathrm{C}$ NMR spectra shows the sharp peak appear at 14 ppm towards higher field nearer to TMS (Tetramethylsilane) correspond to the saturated $\mathrm{sp}^{3}$ hybridized carbon atoms. The peak at 58.11 ppm corresponded to the $\mathrm{sp}^{3}$ hybridized carbon atom attached to quaternary nitrogen. The absorption at 42.83 ppm corresponded to the $\mathrm{sp}^{3}$ hybridized full substituted carbon atom at branching of hydrophobic chain. The absorption at 76.88 and 77.25 ppm corresponded to the carbon atom attached to electronegative oxygen atom which shifts the absorption towards down field. The ${ }^{31} \mathrm{P}$ NMR spectra of C8 $(+)-2-\mathrm{C} 16(+)$ and C8 $(+)-3-\mathrm{C} 16(+)$ gemini surfactants are shown in Supporting Information as representative spectra.

The representative ${ }^{1} \mathrm{H}$ NMR characteristic spectral data are as follows:

2-(2-Ethylhexyloxy)-2-oxo-4-methyl-1, 3, 2-dioxaphos- pholane (2EhOmP)

${ }^{1} \mathrm{H} \mathrm{NMR}, \delta \operatorname{ppm}\left(400 \mathrm{MHz}, \mathrm{CDCl}_{3}, 26{ }^{\circ} \mathrm{C}\right): 0.89(\mathrm{t}, 6 \mathrm{H})$, $1.21(\mathrm{t}, 3 \mathrm{H}), 1.29(\mathrm{~m}, 4 \mathrm{H}), 1.39(\mathrm{~m}, 2 \mathrm{H}), 1.56(\mathrm{~m}, 1 \mathrm{H}), 3.72$ $-3.36(\mathrm{~m}, 1 \mathrm{H}), 3.92(\mathrm{~m}, 2 \mathrm{H}), 4.20-4.05(\mathrm{~m}, 2 \mathrm{H})$.

$N, N$-dimethyl- $N$-ethyl-2-[ [hydroxy (2-Ethylhexyloxy) phosphinyl] oxy]-tetradecanammonium C8 (+)-2-C14 $(+), 3 \mathrm{~b}$

${ }^{1} \mathrm{H}$ NMR, $\delta \mathrm{ppm}\left(400 \mathrm{MHz}, \mathrm{CDCl}_{3}, 26{ }^{\circ} \mathrm{C}\right): 0.81(\mathrm{t}, 6 \mathrm{H})$, $1.36-1.19(\mathrm{~m}, 30 \mathrm{H}), 1.77(\mathrm{~m}, 1 \mathrm{H}), 2.94-2.90(\mathrm{~m}, 2 \mathrm{H})$, $3.41-3.29(\mathrm{~s}, 6 \mathrm{H}), 3.76-3.67(\mathrm{~m}, 2 \mathrm{H}), 3.91-3.85(\mathrm{~m}, 2 \mathrm{H})$, $4.01-3.97$ (m, 2H).

$N, N$-dimethyl- $N$-propyl-2-[ [hydroxy (2-Ethylhexyloxy) phosphinyl] oxy]-hexadecanammonium C8 (+)-3-C16 $(+), 4 \mathrm{c}$

${ }^{1} \mathrm{H} \mathrm{NMR}, \delta \mathrm{ppm}\left(400 \mathrm{MHz}, \mathrm{CDCl}_{3}, 26{ }^{\circ} \mathrm{C}\right): 0.90(\mathrm{t}, 6 \mathrm{H})$, $1.19-1.14(\mathrm{~m}, 3 \mathrm{H}), 1.37-1.22(\mathrm{~m}, 17 \mathrm{H}), 1.62(\mathrm{~m}, 1 \mathrm{H})$, $1.72-1.52(\mathrm{~m}, 2 \mathrm{H}), 3.08-2.83(\mathrm{~m}, 2 \mathrm{H}), 3.31-3.29(\mathrm{~s}, 6 \mathrm{H})$, $3.46-3.32(\mathrm{~m}, 2 \mathrm{H}), 3.78(\mathrm{~m}, 2 \mathrm{H}), 4.0(\mathrm{~m}, 1 \mathrm{H})$.

The formation of zwitterionic gemini surfactants has further been established by ESI-MS (positive ion) mass spectroscopy. As shown in Fig. S9 (see in Supporting Information), the mass-to-charge ratios for peak observed at $\mathrm{m} /$ $\approx 156$ may be attributed to the newly synthesized 2-Chloro2-oxo-4-methyl-1,3,2-dioxaphospholane (COmP) formed by the esterification as depicted in Fig. 1. In addition to this ion peak, the fragment mass ion peak assigned to $\mathrm{m} / \mathrm{z}$ 138.83 was also observed. Figure $\mathbf{S 1 0}$ shows molecular ion peak at $m / z=451$ assigned to the structure of gemini amphiphile $3 a$ surfactant. The other fragments having mass ion peak at $m / z=213,322,430$ were also observed in mass spectrum. The mass ion peak at $m / z=479$ observed in Fig. S11 may be assigned to the structure of $3 \mathrm{~b}$ zwitterionic amphiphile. In addition to this ion peak, the other prominent ions $m / z=242,354,383$ were also observed in the mass spectra of $3 \mathrm{~b}$ zwitterionic gemini amphiphile.

\subsection{Surface activity of zwitterionic amphiphiles}

The surface properties of zwitterionic gemini amphiphiles have been investigated as evidence by standard Wilhelmy platinum plate. The cmc values were determined as a function of surfactant concentration by means of surface tension measurement at an air-liquid interface by noting the inflection in the surface tension values. Figure 4 shows the equilibrium surface tension $(\gamma)$ as a function of the logarithm of concentration ( $\log \mathrm{C}$ ) plots for zwitterionic gemini surfactants in a aqueous solution at $25^{\circ} \mathrm{C}$. As shown in Fig. 4 , the surface tension is decreased initially with increasing concentration of zwitterionic gemini surfactants and then surface tension reached a platue after the increased concentration, indicating distinct breaks to the point on the curve at which a sharp change of the slope occurs corresponds to the cmc. The surface parameters obtained from equilibrium surface tension measurements at an air-liquid interface are summarized in Table 1. The cmc values of 

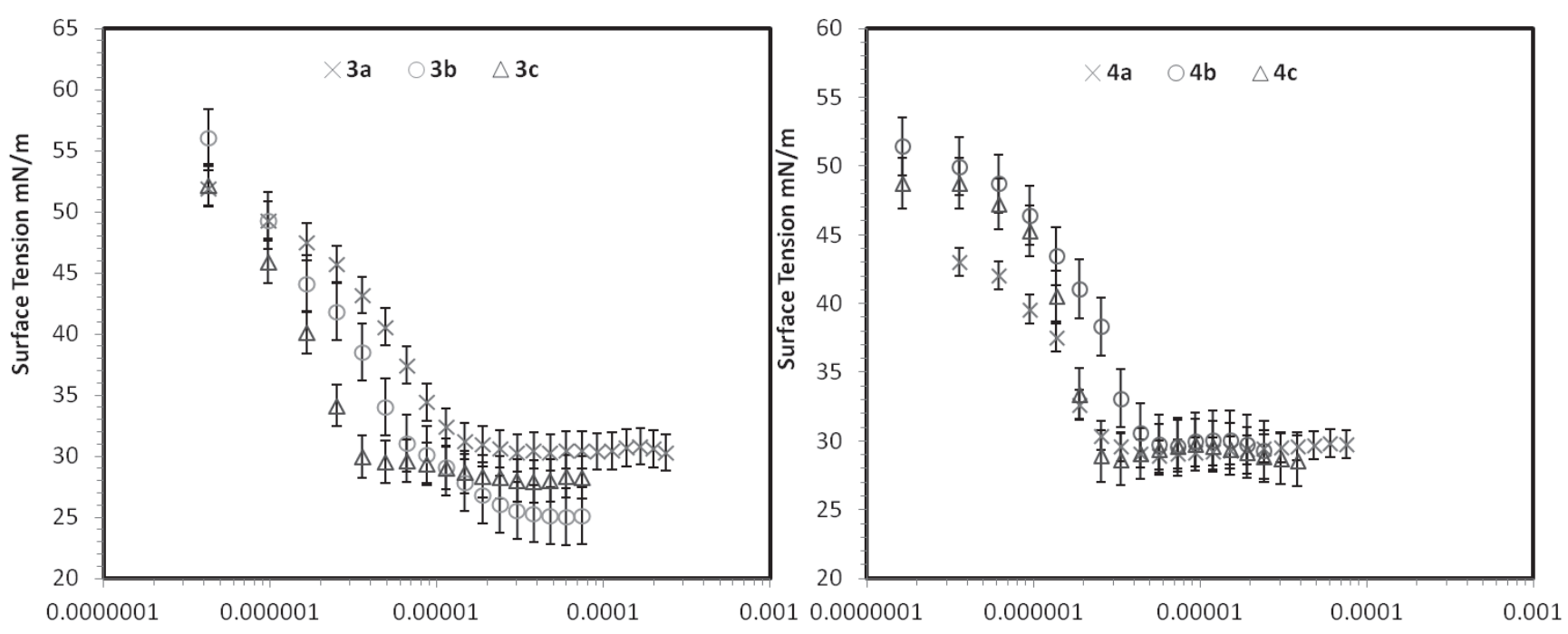

$\log \mathrm{C}$

$\log C$

Fig. 4 Surface tension vs. Log C plot for zwitterionic gemini surfactants.

Table 1 Surface active properties of Zwitterionic Gemini Surfactants.

\begin{tabular}{ccccccc}
\hline \multicolumn{1}{c}{ Surfactants } & $\begin{array}{c}\mathrm{cmc} \\
\mu \mathrm{mol} / \mathrm{L}\end{array}$ & $\begin{array}{c}\gamma_{\mathrm{cmc}} \\
\mathrm{mN} / \mathrm{m}\end{array}$ & $\begin{array}{c}\Gamma_{\max } \times 10^{-10} \\
\mathrm{~mol} / \mathrm{cm}^{2}\end{array}$ & $\begin{array}{c}\mathrm{a}_{\min } \\
\AA^{2}\end{array}$ & $\Pi_{\mathrm{cmc}}$ & $\mathrm{pC}_{20}$ \\
\hline C8(-)-2-C12(+), 3a & 10.3 & 28.00 & 2.41 & 68.63 & 44.09 & 6.95 \\
$\mathrm{C} 8(-)-2-C 14(+), 3 \mathrm{~b}$ & 3.61 & 27.16 & 1.82 & 90.92 & 44.94 & 7.33 \\
$\mathrm{C} 8(-)-2-\mathrm{C} 16(+), 3 \mathrm{c}$ & 3.37 & 27.21 & 1.77 & 93.46 & 44.88 & 7.51 \\
$\mathrm{C} 8(-)-3-\mathrm{C} 12(+), 4 \mathrm{a}$ & 3.90 & 28.30 & 2.09 & 79.19 & 43.80 & 7.03 \\
$\mathrm{C} 8(-)-3-\mathrm{C} 14(+), 4 \mathrm{~b}$ & 3.44 & 28.26 & 2.99 & 55.36 & 43.83 & 7.05 \\
C8(-)-3-C16(+), 4c & 3.43 & 27.39 & 8.31 & 19.96 & 44.71 & 6.03 \\
$\mathrm{C} 8 \mathrm{~L}(-)-2-\mathrm{C} 12(+)$ & 23.3 & 29.945 & 4.11 & 40.32 & 42.15 & 5.82 \\
C8L(-)-2-C14(+) & 17.7 & 27.562 & 4.88 & 33.99 & 44.53 & 5.87 \\
\hline
\end{tabular}

L refers to linear chain length; cmc refers to critical micelle concentration from surface tension measurements; $\gamma_{\mathrm{cmc}}$, surface tension at the cmc; $\Gamma_{\max }$, maximum surface excess concentration; $\mathrm{a}_{\min }$, minimum area per molecule at the interface; $\Pi_{\mathrm{cmc}}$, effectiveness of surfactant reduction; $\mathrm{pC}_{20}$, efficiency of adsorption.

these zwitterionic gemini surfactants were found to be depending on the nature of spacer moiety (influences of methyl group on spacer), the quaternary counterpart and the polarity of the headgroup considerably influences the cmc values of these gemini surfactants.

The zwitterionic gemini surfactants: $3 \mathrm{a}, 3 \mathrm{~b}$, and $3 \mathrm{c}$ have shown the typical inclination of a cmc decreased with increasing tail length, but there is smaller effect of increasing tail length than desired (see Table 1). This similar effect was also reported by Menger ${ }^{24)}$ for the smaller effect of a decreasing cmc with increasing effective chain length. The cmc values of these gemini surfactants decrease as C8(-) $-2-\mathrm{C} 16(+)>\mathrm{C} 8(-)-2-\mathrm{C} 14(+)>\mathrm{C} 8(-)-2-\mathrm{C} 12(+)$. In other words, as the hydrophobic chain length increases from 12 to 16 at the cationic moiety, the cmc decreases for $3 a, 3 b$, and 3c surfactants. Similarly, the branched analogue reported by Menger ${ }^{24)}$ where one linear chain with a carbon number of 9, 10 or 12 . The effect of decreasing cmc was also observed in the $4 \mathrm{a}, 4 \mathrm{~b}$, and $4 \mathrm{c}$ amphiphiles having branched spacer i.e. influence of methyl group on spacer. The cmc values of these branching amphiphiles decreases in order as C8 (-)-3-C16(+) > C8 (-) -3-C14(+) >C8 (-) $-3-\mathrm{C} 12(+)$. As shown in Table 1, the effect of influence of methyl group on spacer of these amphiphiles on the cmc is remarkable as compared with the linear chain length analogue i.e. C8L(-)-2-C12(+) and C8L(-)-2-C14(+) and branched zwitterionic gemini surfactants reported earlier by Menger ${ }^{23,24)}$. This linear and branched counterpart has much higher values of both cmc and $\gamma_{\mathrm{cmc}}$. Comparing the Menger's zwitterionic analogue ${ }^{16,23,24)}$ with present 
branched spacer zwitterionic counterparts, shows that the former exhibits a cmc twenty times higher than the cmc of the latter (see Table 1). It is interesting to note that the zwitterionic gemini surfactant: C8(-)-2-C12(+ ) closely resemble its structural analogue C8(-)-3-C12(+); a branching amphiphile having branched spacer in-between two non identical headgroups with a difference, as the former is an ethylene spacer and latter is influence of methyl group on spacer as compared with Manger's zwitterionic amphiphiles. However the cmc values of these surfactants considerably differ from one another as the cmc of C8 (-) $-3-\mathrm{C} 12(+)$ is lower compared to C8 $(-)-2-\mathrm{C} 12(+)$. As compared with the cmc of linear and branched amphiphiles, reported previously by Menger and coworkers et $a l .{ }^{16,23,24)}$, has higher cmc than present synthesized branched zwitterionic gemini amhiphiles. This indicates that the branched hydrophobic tail and an impact of methyl group on spacer consisting amphiphiles had great efficiency in lowering cmc and $\gamma_{\mathrm{cmc}}$, which is one of the remarkable key properties of zwitterionic gemini surfactants in aqueous medium, which could enable the reduction of surfactant consumption in waterborne chemical products. This shows that influence of methyl group on spacer and chain branching brings about a decrease in $\mathrm{cmc}$ and $\gamma_{\mathrm{cmc}}$, a result that is not necessarily to be expected. As depicted in Table 1, all zwitterionic gemini surfactants decreases the surface tension to a great extent which is solely attributed to a tighter packing of the longer hydrophobic chains at air/water interface $^{25,26)}$.

As shown in Fig. 4, the surface activity of zwitterionic gemini amphiphiles was determined by the plot of equilibrium surface tension inflection reached a final plateau, versus logarithmic concentrations indicating well defined cmc and $\gamma_{\mathrm{cmc}}$. The several adsorption physicochemical parameters were determined from the $\gamma$ vs. Log C plots (Fig. 4) for the contrast to the parameters reported. By applying Gibbs adsorption law to the equilibrium surface tensions allows the calculation of adsorption parameters at air/water interface. According to the Gibbs adsorption isotherm ${ }^{27)}$, maximum surface excess concentration $\left(\Gamma_{\max }\right)$ at air/water interface has been determined from equation (1).

$$
\Gamma_{\max }=-\frac{1}{2.303} \mathrm{nRT}\left(\frac{\partial \gamma}{\partial \log \mathrm{C}}\right)_{\mathrm{T}}
$$

where $\gamma$ is the surface tension in $\mathrm{mN} / \mathrm{m}, \Gamma_{\max }$ is the adsorbed amount of surfactant per unit area at the air/water interface after complete monolayer formation and $\Gamma_{\max }$ is given in units of $\mathrm{mol} / \mathrm{cm}^{2}$, T is absolute temperature $\mathrm{K}, \mathrm{R}$ is the gas constant $\mathrm{R}=8.314 \mathrm{~J} \mathrm{~mol}^{-1} \mathrm{~K}^{-1}$, and $\mathrm{C}$ is the surfactant concentration. The value of $n$, the number of adsorption species i.e. ionic species at the air/water interface, whose concentration changes with surfactant concentration at the interface taken as unity for zwitterionic gemini surfactants. These gemini amphiphiles contains no counterions can, therefore, be considered as neutral molecule, which lead to $\mathrm{n}=1$. $\Gamma_{\max }$ was calculated from the slope of the surface tension versus logarithmic concentration plots when the concentration is reached plateau region. Increasing the accumulation of surfactant molecules at the air/ water interface indicates the repulsion in the bulk of the solution between surfactant and water which moves the surfactants molecule to the air/water interface.

The minimum area occupied per surfactant molecule at the air/water interface $\left(\mathrm{a}_{\min }\right)$ can be estimated by using following equation:

$$
\mathrm{a}_{\min }=1 / \mathrm{N}_{\mathrm{A}} \Gamma_{\text {max }}
$$

where $N_{A}$ is Avogadro's number and $a_{\min }$ is given in units of $\AA^{2}$

The calculated area occupied by the surfactants molecule at air/water interface $\left(\mathrm{a}_{\text {min }}\right)$ was greatly influenced by the tail length. The typical pattern shows that $a_{\text {min }}$ values increases with increasing the hydrophobic tail length at interface. As shown in Table 1, the increased hydrophobic tail lengths of the zwitterionic gemini molecules influence the adsorption, the $\Gamma_{\max }$ decreases and consequently $\mathrm{a}_{\min }$ increases.

Comparing the zwitterionic gemini surfactants $4 a, 4 b$, and $4 c$ having influence of methyl group on spacer moiety had lower $a_{\text {min }}$ values than $3 a, 3 b$, and $3 c$ surfactants and reported Menger's Zwitterionic geminis ${ }^{16,23,24)}$ having linear spacer reported in Table 1. Lower $\mathrm{a}_{\min }$ values of $4 \mathrm{a}, 4 \mathrm{~b}$, and $4 \mathrm{c}$ indicated greater tendency to form micelles rather than adsorbing at air/water interface contrasting the $3 \mathrm{a}, 3 \mathrm{~b}$, and $3 c$ gemini surfactants. The $a_{\min }$ values of $3 a, 3 b$, and $3 c$ surfactants increases with increasing hydrophobic tail length. In the newly synthesized $4 \mathrm{a}, 4 \mathrm{~b}$, and $4 \mathrm{c}$ surfactants i.e. influence of methyl group on spacer moiety, an unusual pattern of $\mathrm{a}_{\min }$ values was demonstrated, decrease in $\mathrm{a}_{\min }$ values with increase in tail length. It can be because of the $4 \mathrm{a}, 4 \mathrm{~b}$, and 4c having anionic and cationic hydrophilic heads connected with the branched spacer differ from $3 a$, $3 b$, and $3 c$ surfactants and Menger's reported zwitterionic geminis $^{16,23,24)}$. This is compatible with the expectation that the spacer moiety would have a more considerable effect on the hydrophilic group area for gemini surfactants with longer spacer groups, which are known to become adsorbed into the micellar core. Unlike the synthesized bispyridinium gemini surfactants reported by Fisicaro et $a l$, amin values of these surfactants increases with increasing spacer length ${ }^{28,29)}$. Such a pattern of increase in $a_{\text {min }}$ values with increasing spacer length was also observed by Menger et $a l .^{22)}$ for linear chain length zwitterionic gemini analogues and Zana et $a l .{ }^{30)}$ for gemini quaternary ammonium surfactants. The prime factor responsible for the deviation of $\mathrm{a}_{\text {min }}$ values with spacer is the balance attractive interactions between tails and repulsive interactions between heads suggested by a theoretical model ${ }^{31,32)}$.

We further estimated the efficiency of surface tension 
reduction $\mathrm{pC}_{20}$. The $\mathrm{pC}_{20}$ values were calculated from the negative logarithm of the surfactant concentration required to reduce the surface tension of pure water by $20 \mathrm{mN} / \mathrm{m}$ and also measured from the $\gamma v s$. Log C plots. It was clearly indicated that the increase in chain length at hydrophobic counterparts resulted in lower cmc and lager $\mathrm{pC}_{20}$ values. Lager values of $\mathrm{pC}_{20}$ attributed to greater tendency of the surfactants to adsorb at air/water interface relative to its tendency to form micelles. As concluded from $\mathrm{a}_{\text {min }}$ values, similar effect was also exhibited by the $\mathrm{pC}_{20}$ values that the newly synthesized $4 \mathrm{a}, 4 \mathrm{~b}$, and $4 \mathrm{c}$ surfactants have greater tendency to form micelles as compared with the gemini surfactants $3 \mathrm{a}, 3 \mathrm{~b}$, and $3 \mathrm{c}$ and Menger's reported zwitterionic geminis ${ }^{16,23,24)}$, because of the unusual pattern of $\mathrm{pC}_{20}$ values being observed (see Table 1).

Figure 5 show the plot of $\log \mathrm{C}_{20}\left(-\mathrm{pC}_{20}\right)$ values versus $\mathrm{n}$ (Carbon number 12 or 14 or 16) for the zwitterionic gemini surfactant with spacer value $S=2$ or 3 . For $S=2$; $3 a, 3 b$, and $3 c$ surfactants, the $\log \mathrm{C}_{20}$ value decreased steadily as $\mathrm{n}$ increased at cationic counterpart, whereas, for $\mathrm{S}=3 ; 4 \mathrm{a}$, $4 \mathrm{~b}$, and $4 \mathrm{c}$ surfactants, Log $\mathrm{C}_{20}$ value increased in small change as $n$ increased at $n=14$ and more effectively increased at $n>14$.The deviation when $S=3$ for the longer chain compound was the result of the decrease in monomer activity upon premicellar aggregation of the geminis $^{33)}$.

The Gibbs free energy of micellization $\left(\Delta G_{\text {mic }}^{\circ}\right)$ and ad$\operatorname{sorption}\left(\Delta G_{\text {ads }}^{\circ}\right)$ was calculated with the following equations $^{34)}$ :

$$
\begin{aligned}
& \Delta G_{\text {mic }}^{\circ}=\mathrm{RT} \ln \mathrm{X}_{\mathrm{cmc}} \\
& \Delta G_{\text {ads }}^{\circ}=\Delta G_{\text {mic }}^{\circ}-\left(\Pi_{\mathrm{cmc}} / \Gamma_{\text {max }}\right)
\end{aligned}
$$

where $\mathrm{X}_{\mathrm{cmc}}$ is the molar fraction of $\mathrm{cmc}, \mathrm{X}_{\mathrm{cmc}}=\mathrm{cmc} / 55.4$, where the $\mathrm{cmc}$ is in $\mathrm{mol} / \mathrm{L}$ and 55.4 is the molar concentration of water i.e. $1 \mathrm{~L}$ of water corresponding to 55.4 moles

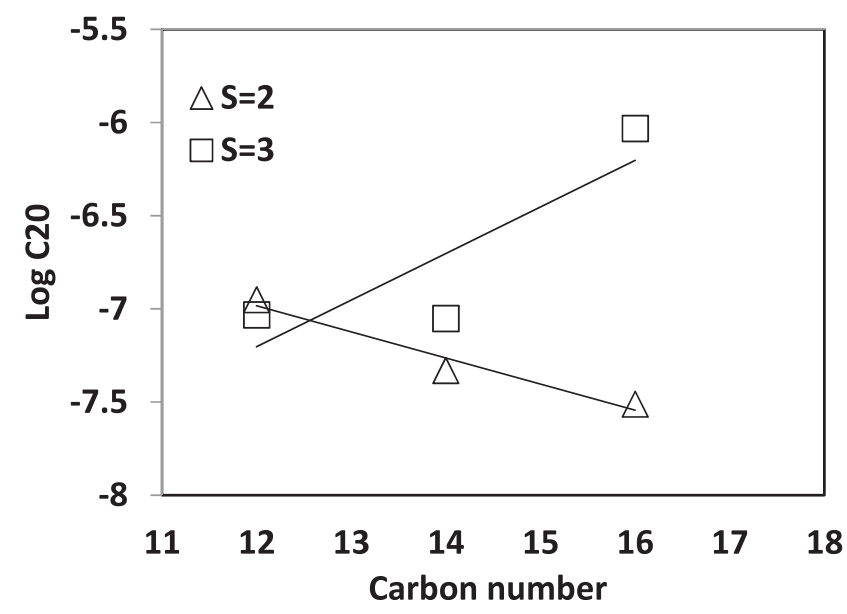

Fig. 5 Log $\mathrm{C}_{20}$ versus $n$ plots for the zwitterionic geminis with $\mathrm{S}=2$ or 3 . of water at $25^{\circ} \mathrm{C}$. In equation $(4) \Pi_{\mathrm{cmc}}$ denotes the effectiveness of surface tension (surface pressure) at $\mathrm{cmc}, \Pi_{\mathrm{cmc}}$ was determined by following equation 5

$$
\Pi_{\mathrm{cmc}}=\gamma_{0}-\gamma_{\mathrm{cmc}}=20 n \mathrm{RT} \Gamma_{\max } \ln \left(\mathrm{cmc} / \mathrm{C}_{20}\right)
$$

where the $\gamma_{0}$ and $\gamma_{\mathrm{cmc}}$ are the surface tension of pure water and the surfactant solution at cmc respectively. The $\gamma_{\mathrm{cm}}$ values of surfactants reflected their $\mathrm{cmc} / \mathrm{C}_{20}$ ratio according to equation (5). Here, the $\mathrm{cmc} / \mathrm{C}_{20}$ ratio is a measure of the tendency to form micelles relative to the tendency to adsorb at the air/water interface (see Table 2). Lager the value of $\mathrm{cmc} / \mathrm{C}_{20}$ ratio greater is the tendency of the surfactant to adsorb at air/water interface, relative to its tendency to form micelles ${ }^{27)}$. The adsorption and aggregation properties of surfactants are estimated many times from the $\mathrm{pC}_{20}$ and $\mathrm{cmc} / \mathrm{C}_{20}$ ratio values. That can be correlated to structural factors regarding the adsorption and micellization processes, respectively. We have noticed that the zwitterionic gemini surfactants: $4 \mathrm{a}, 4 \mathrm{~b}, 4 \mathrm{c}$ has lower $\mathrm{cmc} / \mathrm{C}_{20}$ ratio compared to gemini amphiphiles: $3 a, 3 b, 3 c$. This was indicating that the nature of the headgroup and addition of methyl group on spacer moiety influences the aggregation behavior of the surfactants in aqueous solution.

The negative Gibbs free energy of micellization $\left(\Delta G_{\text {mic }}^{\circ}\right)$ and adsorption $\left(\Delta G_{\text {ads }}^{\circ}\right)$ for synthesized zwitterionic gemini surfactants indicates the processes are spontaneous. As shown in Table 2, the value of $\Delta G_{\text {ads }}^{\circ}$ is more negative than $\Delta G_{\text {mic }}^{\circ}$ which is evident of the adsorption tendency of an individual surfactant being greater than the micellization at air/water interface is attributed to the adsorption deals with thermodynamic characteristics of surfactant molecule at interface. In other words, the hydrophobicity of the molecules projects them towards the air/water interface and micellization took place after surface adsorption ${ }^{30)}$. In our study, the smaller energy gap between $\Delta G_{\text {mic }}^{\circ}$ and $\Delta G_{\text {ads }}^{\circ}$ in the individual zwitterionic gemini surfactant indicated greater tendency to aggregate in solution rather than adsorbing at the air/water interface. We observed the direct relation between the $a_{\min }$ value and the free energy gap, that smaller calculated $a_{\min }$ value is proportional to the smaller free energy gap of individual surfactant for zwitterionic gemini surfactants ${ }^{35)}$ (see in Table 2).

Table 2 Thermodynamic properties of synthesized zwitterionic gemini surfactants.

\begin{tabular}{crcc}
\hline Surfactants & \multicolumn{1}{c}{$\mathrm{cmc} / \mathrm{C}_{20}$} & \multicolumn{1}{c}{$\Delta G_{\text {mic }}^{\circ}$} & \multicolumn{1}{c}{$\Delta G_{\text {ads }}^{\circ}$} \\
\hline $\mathrm{C} 8(-)-2-\mathrm{C} 12(+), 3 \mathrm{a}$ & 91.89 & -38.37 & -57.85 \\
$\mathrm{C} 8(-)-2-\mathrm{C} 14(+), 3 \mathrm{~b}$ & 77.16 & -40.97 & -62.67 \\
$\mathrm{C} 8(-)-2-\mathrm{C} 16(+), 3 \mathrm{c}$ & 109.04 & -41.14 & -64.05 \\
$\mathrm{C} 8(-)-3-\mathrm{C} 12(+), 4 \mathrm{a}$ & 41.80 & -40.78 & -59.59 \\
$\mathrm{C} 8(-)-3-\mathrm{C} 14(+), 4 \mathrm{~b}$ & 38.63 & -41.12 & -56.83 \\
$\mathrm{C} 8(-)-3-\mathrm{C} 16(+), 4 \mathrm{c}$ & 3.67 & -41.1 & -46.76 \\
\hline
\end{tabular}




\subsection{Conductivity measurements}

The surface and thermodynamics parameters of the zwitterionic gemini surfactants have also been evaluated by investigating the variation in conductivity of the respective surfactant in aqueous solution at various concentrations. The investigated cmc values were in good agreement and have been followed similar trend with those determined by surface tension measurements. The $\mathrm{cmc}$ values of these newly synthesized di-ester containing gemini surfactants are comparable to other heterogemini surfactants having a great variety of anionic-cationic, anionic-nonionic, nonionic-nonionic gemini surfactants as well as conventional quaternary gemini surfactants and these gemini surfactants are equivalently good as other recently developed
$\mathrm{C} 8-2-\mathrm{C} 12$

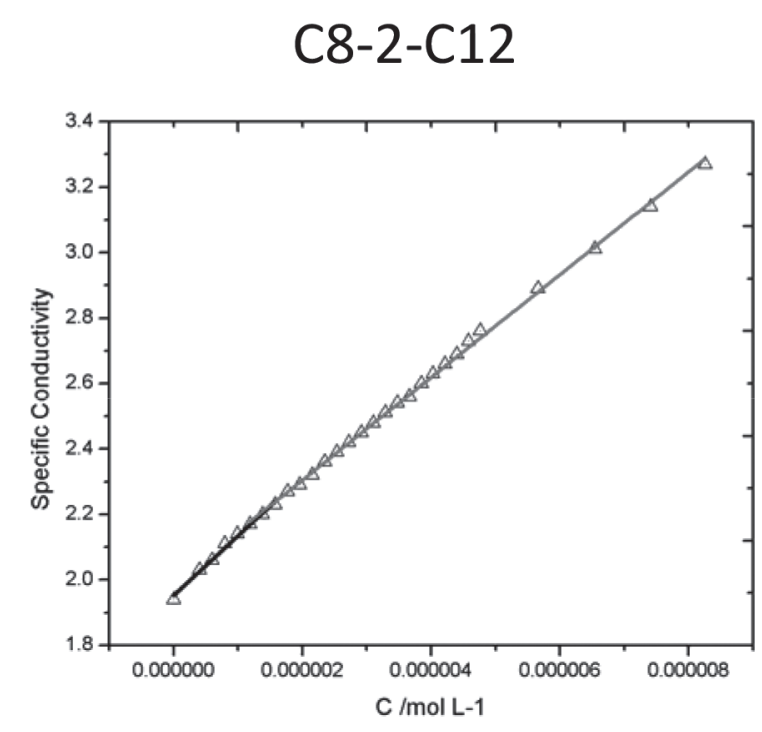

$\mathrm{C} 8-3-\mathrm{C} 12$

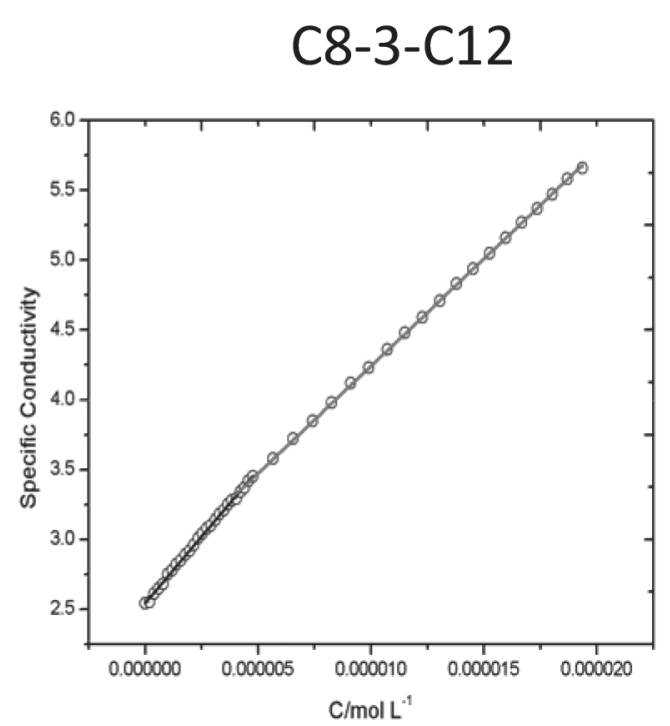

zwitterionic gemini surfactants ${ }^{14-18)}$. However the basic focus of this work is to study the branching effect of hydrophobic tail attached to the phosphate group with varying spacer and tail attached to quaternary nitrogen entities on self-aggregation and thermodynamic properties, which has hardly ever been investigated. The specific conductivity values of these newly synthesized gemini surfactants are displayed as a function of molar concentration in aqueous solutions investigated at $25^{\circ} \mathrm{C}$ (Fig. 6). These were useful in figure out the self-aggregation and thermodynamic parameters for these new di-ester based surfactants having non identical headgroups (Table 3). We have observed that the nature of the headgroup and spacer moiety influences the aggregation behavior of the surfactants in aqueous so-

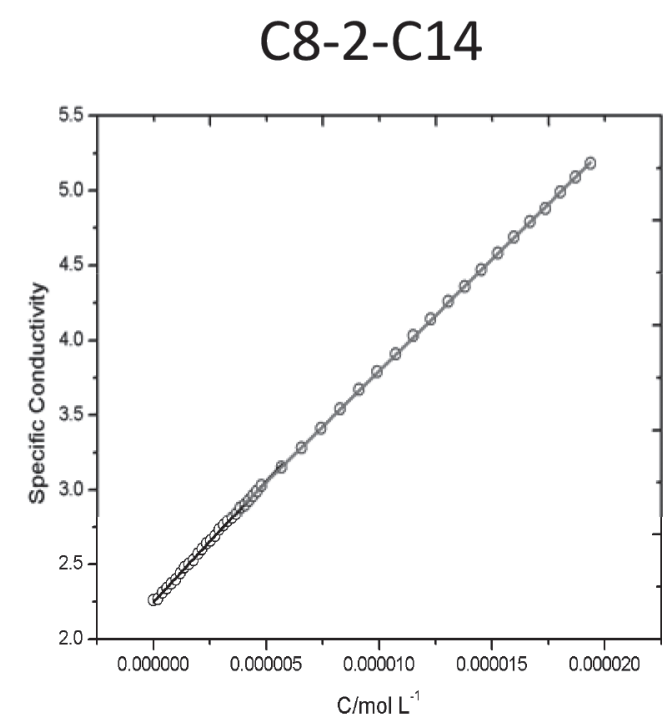

C8-3-C14

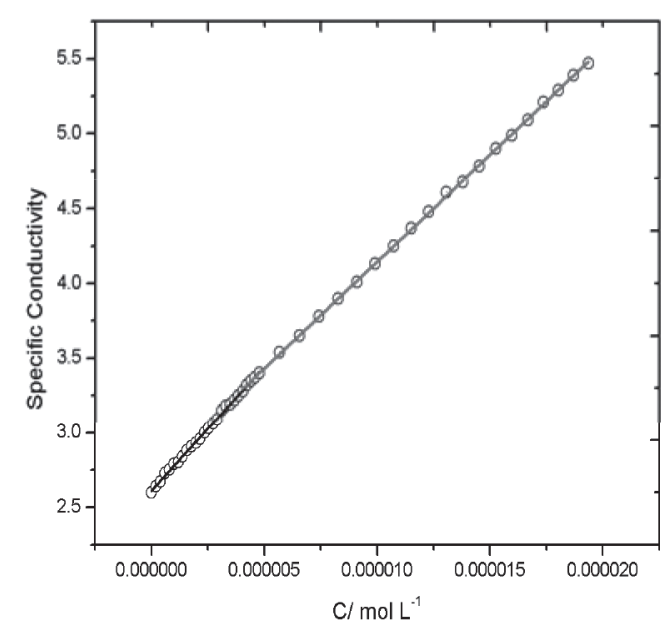

Fig. 6 Specific conductivities of $\mathrm{C} 8(-)-2-\mathrm{Cn}(+)$; where $\mathrm{n}=12,14$ and 16 , solutions as a function of surfactant concentration at $25^{\circ} \mathrm{C}$. 
Table 3 The Surface and thermodynamic properties of gemini surfactants determined by the electrical conductivity method at $25^{\circ} \mathrm{C}$.

\begin{tabular}{cccccc}
\hline Surfactants & $\begin{array}{c}\mathrm{cmc} \\
(\mu \mathrm{mol} / \mathrm{L})\end{array}$ & $\alpha$ & $\beta$ & $\Delta G_{\text {mic }}^{\circ}$ & $\Delta G_{\text {ads }}^{\circ}$ \\
\hline $\mathrm{C} 8(-)-2-\mathrm{C} 12(+), 3 \mathrm{a}$ & 4.51 & 0.88 & 0.12 & -14.54 & -32.84 \\
$\mathrm{C} 8(-)-2-\mathrm{C} 14(+), 3 \mathrm{~b}$ & 4.95 & 0.92 & 0.08 & -13.49 & -38.18 \\
$\mathrm{C} 8(-)-2-\mathrm{C} 16(+), 3 \mathrm{c}$ & 3.95 & 0.77 & 0.23 & -17.35 & -42.71 \\
$\mathrm{C} 8(-)-3-\mathrm{C} 12(+), 4 \mathrm{a}$ & 4.34 & 0.80 & 0.20 & -16.33 & -37.29 \\
$\mathrm{C} 8(-)-3-\mathrm{C} 14(+), 4 \mathrm{~b}$ & 4.46 & 0.85 & 0.15 & -15.12 & -29.78 \\
$\mathrm{C} 8(-)-3-\mathrm{C} 16(+), 4 \mathrm{c}$ & 4.18 & 0.82 & 0.18 & -16.08 & -21.46 \\
\hline
\end{tabular}

lution.

The degree of counterion binding $(\beta)$ can be calculated from the following equation which represents the negatively charged counter ions associated with the micelles in aqueous solution.

$$
\beta=(1-\alpha)
$$

where $\alpha$ is the degree of ionization and which is determined from the ratio of the slope above and below the indicative of cmc value. Recent studies shows that the calculated $\beta$ values of gemini amphiphiles are do not follow any particular trend and are frequently independent on a structural difference between surfactants i.e. nature of counterions, hydrophobic tail length and change in spacer moiety $^{14-18)}$. The calculated $\beta$ values for the zwitterionic gemini surfactants represent the counter ions that are present in the Stern layer of the micelles to counterbalance the electrostatic force that opposes micelle formation. Since the aggregation of monomers solely depend on the hydrophobic van der Waals interactions, headgroups repulsion, the hydrophobic hydration, and the linked spacer moiety energies but not only on electrostatic force. Therefore, the $\beta$ values deduced from the degree of ionization are helpful in calculating the thermodynamic properties of the surfactants.

From Table 3, we have noticed that the $\beta$ values of the zwitterionic gemini amphiphiles with $\mathrm{C} 12$ hydrophobic alkyl chains are slightly less than those with C14 hydrophobic alkyl chains at the identical spacer group length. Moreover, the determined $\beta$ value decreases with the shortening of the spacer unit length. These consequences should be mainly attributed to the change of surface charge density of the micelles. The di-ester based zwitterionic gemini surfactants having two non identical head groups are connected covalently and are packed more closely through a shorter spacer moiety, which bring the charge density to increase ${ }^{36)}$. Accordingly, the degree of dissociation $(\beta)$ is reduced appreciably as a consequence of the electrostatic interactions between surfactant ions and counter ions are improved. Therefore, the contributions arising from the change in hydrophobic group have very little impact on the determined parameter. However when compared to the branched spacer analogue of these zwitterionic gemini surfactants i.e. $4 \mathrm{a}, 4 \mathrm{~b}, 4 \mathrm{c}$, determined $\beta$ values shows a change may be due to involvement occurring from linear spacer moiety which is typically different from branched spacer analogue.

The standard Gibbs free energy for micellization $\left(\Delta G_{\text {mic }}^{\circ}\right)$ can be calculated from specific conductivity data followed by equation (7)

$$
\Delta G_{\text {mic }}^{\circ}=\mathrm{RT}(1+\beta) \ln \mathrm{X}_{\text {cmc }}
$$

where $\beta$ is the degree of counterions binding to micelles and $X_{\mathrm{cmc}}$ is the molar fraction of cmc described earlier. The $\Delta G_{\text {mic }}^{\circ}$ represents the work done to transfer the monomeric form of surfactants from the air-water interface to the micellar phase in the bulk solution. The micellization of di-ester containing zwitterionic gemini surfactants is a spontaneous process at the deliberated $\Delta G_{\text {mic }}^{\circ}$ values are negative. We have noticed that the determined thermodynamic parameter has slight dependence on the nature of branched hydrophobic tail and spacer unit. The standard Gibbs free energy for micellization does not considerably change with the change in hydrophobic alkyl chain length and spacer moiety. However, the zwitterionic amphiphiles with ethylene spacer moiety has entirely lower $\Delta G_{\text {mic }}^{\circ}$ value compared to its branched analogues.

The Gibbs free energy of adsorption $\Delta G_{\text {ads }}^{\circ}$ indicates the free energy to transfer surfactants in solution to the airwater interface and is calculated by equation(4), which is described earlier. Here we have observed that the $\Delta G_{\text {ads }}^{\circ}$ for these zwitterionic gemini surfactants depends on the nature of the hydrophobic alkyl chain length and spacer unit and its absolute value generally decreases as in linear spacer analogue: $\mathrm{C} 8(-)-2-\mathrm{C} 16(+)>\mathrm{C} 8(-)-2-\mathrm{C} 14(+)>\mathrm{C} 8$ $(-)-2-\mathrm{C} 12(+)$ and in branched analogue: $\mathrm{C} 8(-)-3-\mathrm{C} 12(+)$ $>\mathrm{C} 8(-)-3-\mathrm{C} 14(+)>\mathrm{C} 8(-)-3-\mathrm{C} 16(+)$. The linear spacer analogue: $\mathrm{C} 8(-)-2-\mathrm{C} 16(+)$ has the lowest negative value of $\Delta G_{\text {ads }}^{\circ}$ signifying that this surfactant has the greater tendency to adsorb at the air-water interface followed by the gemini amphiphiles: C8(-)-2-C14(+), C8(-)-3-C12(+) . It has been observed that the branched spacer analogue have 
a lower $\Delta G_{\text {ads }}^{\circ}$ value compared to its linear one and the values also depend on the nature of spacer moiety and the quaternary counterpart hydrophobic chain length.

\subsection{Dye micellization}

The visible absorption spectrum of $\mathrm{EY}$ in aqueous solution appears at $517 \mathrm{~nm}$ (represented as $\left.\lambda_{\max }\right)$. The binding effect of anionic Eosin-Y dye (structure shown in Fig. 2) with the synthesized zwitterionic gemini surfactant aggregates in aqueous solution was investigated by UV-Visible spectroscopy at wavelength $\left(\lambda_{\max }\right) 517 \mathrm{~nm}$ of the EY dye. A stock solution of $\mathrm{EY}(1 \mu \mathrm{mol} / \mathrm{L})$ was used to perform experimental work and stored in dark at $4^{\circ} \mathrm{C}$. All the stock solutions were used within a week of preparation. This fixed concentration is sufficiently low that to have no aggregation of dye. The molar absorptivity $\left(\varepsilon_{0}\right)$ of EY dye at wavelength of $517 \mathrm{~nm}$ was calculated as $8.9 \times 10^{4} \mathrm{M}^{-1} . \mathrm{cm}^{-1}$ at $25^{\circ} \mathrm{C}$ with correlation $\mathrm{R}^{2}=0.998$ indicates that the $\mathrm{EY}$ dye concentration was obeyed the Beer-Lambert Law at various ranges of benefits. The binding effect of dye and surfactants aggregates was investigated by recording the absorption spectra at different surfactants concentrations varied from $1.0 \times 10^{-6}$ to $1.0 \times 10^{-3} \mathrm{~mol} / \mathrm{L}$. Figure 7 describes the changes in absorbance values of EY dye with the concentrations of zwitterionic gemini surfactants.

The interaction of EY dye and the surfactant aggregates causes the deviation in absorption spectrum depending on surfactants concentration. Initially, the absorbance value of $\mathrm{EY}$ at $517 \mathrm{~nm}$ is decreased with the progressive addition of surfactant concentration reached a minimum value which is considered as optimum concentration value for respective surfactants. After then, it starts to increase again with further increase in surfactant concentration. Finally, the absorbance value of EY dye attained maximum than that of dye solution without surfactant and there was increase in absorbance value which attained maximum $\lambda_{\max }$ value of dye solution. The shifting of $\lambda_{\max }$ value of fixed concentration of EY dye with varying concentrations of 3b surfactant are shown in Fig. 8 as a representative plot, because same pattern have been observed in other zwitterionic gemini surfactants. The $\lambda_{\max }$ values are summarized in Table 4 . The obtained optimum concentration: $1,0.04$ and $0.01 \mathrm{mM}$ respectively for linear spacer analogue and 0.4, 0.04 and $0.01 \mathrm{mM}$ respectively for branched spacer analogue as depicted in Fig. 7. The decrease in values of absorbance of EY dye can be assumed due to complex formation between dye and surfactants.

The hydrophobic tail length of the zwitterionic gemini surfactants affects the micelles. For instance, cmc increased with decrease in tail length, and the decrease in micelle dissociation was resulted into the thickness of stern layer. Thus Stern layers are more ionic in comparison with their respective lower hydrophobic tail counterparts ${ }^{37)}$. In linear spacer series change in absorbance was higher for

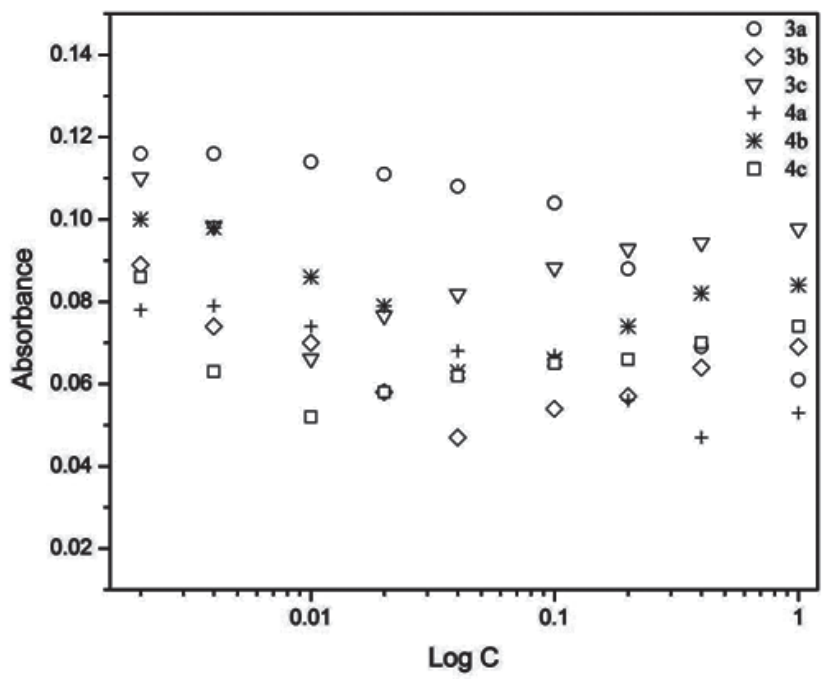

Fig. 7 The binding effect of zwitterionic gemini surfactants concentration on the absorbance value of $\mathrm{EY}$ at $517 \mathrm{~nm}$.

C8 (-)-2-C16(+) surfactant solution that contains maximum hydrophobic alkyl chain length than the others. Similar effect was also observed in branched series that the C8 (-)-3-C16 (+) has largest change in absorbance than other analogue. Thus we can conclude that the complex formation tendency of dye and surfactant increases with increasing hydrophobic tail chain length of surfactants ${ }^{38)}$. This behavior of surfactants is attributed to obey the Traube's rule ${ }^{39}$. The interaction of dye molecule and surfactants aggregate become stronger with increase in alkyl chain length of surfactants, which demonstrate the importance of hydrophobic forces ${ }^{40)}$. The complex formation of the EY dye and zwitterionic gemini surfactants is a consequence of mutual influences of electrostatic and hydrophobic interactions. In aqueous solution they dissociate into ions and therefore van der Waals interactions can emerge between adjacent surfactants head groups and carboxylate group of EY dye. The negative charge of carboxylate group of dye is delocalized and distributed over the terminal carboxylate group and the hydrophobic aromatic ring; thus the positive charged quaternary end of the surfactants will tend to interact electrostatically on which the charge is localized. The carboxylate group of dye will therefore be covered deeper in the micelle Stern layer leading to moderated electrostatic interaction between the charged surfactants head groups and carboxylate groups of EY dye.

The maximum absorbance value at increasing surfactant concentrations attributed to increase in the amount of the dye molecules which are taken up in the micelles ${ }^{41}$. As shown in Fig. 8, the absorbance and the value of $\lambda_{\max }$ reached the maximum value with further increase in surfactants concentration above micellar region attributed that all EY dye molecules are characterized by dividing into 
A
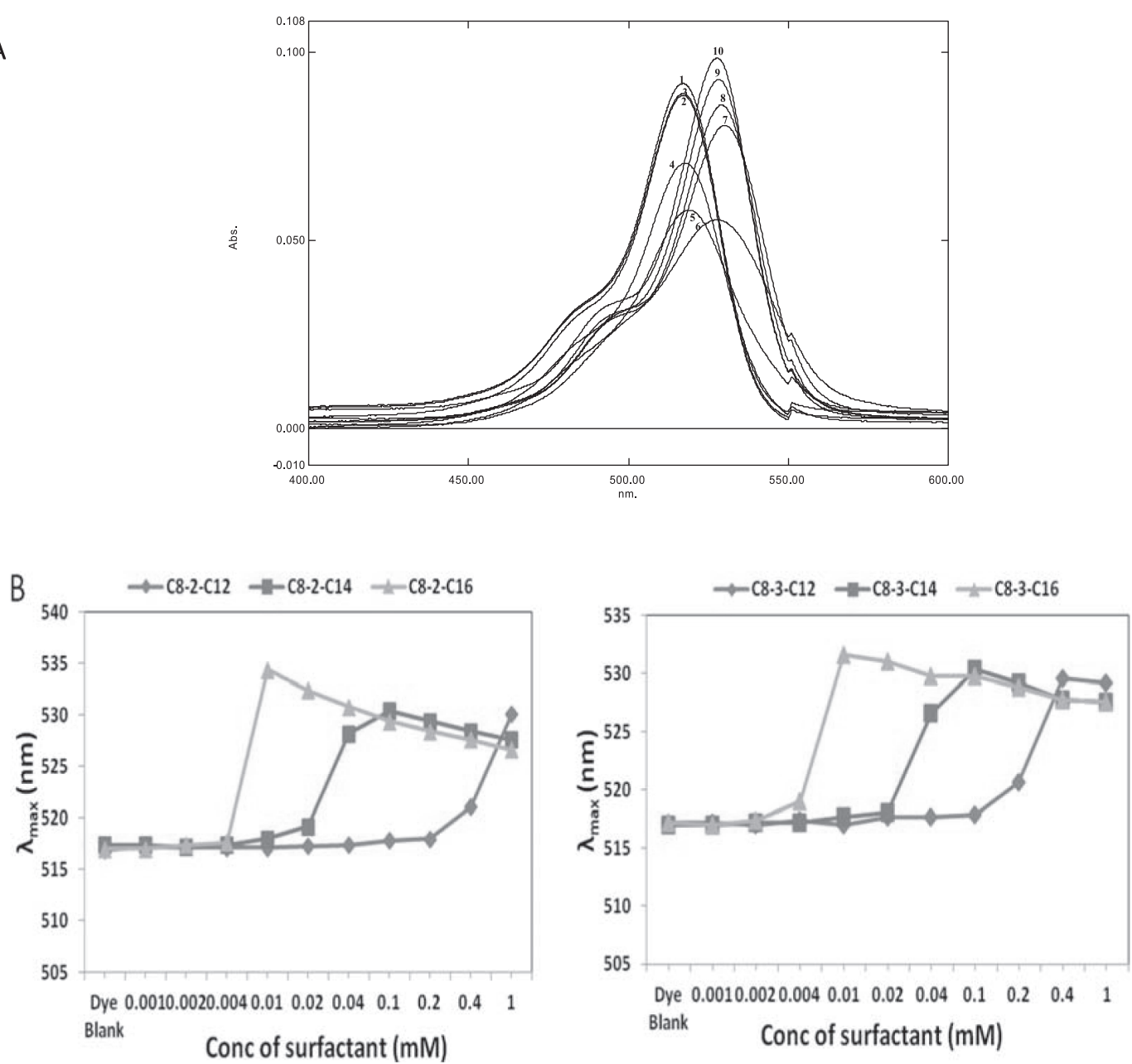

Fig. 8 A) Absorption spectra of EY dye at various concentrations of C8 $(-)-2-\mathrm{C} 14(+)$ surfactant at $25^{\circ} \mathrm{C}$. Concentrations of C8 (-) -2-C14(+) $\mathrm{mol} \mathrm{L}^{-1}$; below the CMC: (1)EOY $1 \times 10^{-6}$; (2) $2 \times 10^{-6}$; (3) $4 \times 10^{-6}$; (4) $1 \times 10^{-5}$; (5) $2 \times 10^{-5}$; (6) 4 $\times 10^{-5}$; (7) $1 \times 10^{-4}$; (8) $2 \times 10^{-4}(9) 4 \times 10^{-4}(10) 1 \times 10^{-3} \mathrm{~mol} \mathrm{~L}^{-1}$. B) Changes in $\lambda_{\max }$ at various concentrations of surfactants.

Table 4 Several spectral parameters of EY in aqueous micellar solution.

\begin{tabular}{clc}
\hline Surfactants & $\begin{array}{c}\lambda_{\max } \\
(\mathrm{nm})\end{array}$ & $\begin{array}{c}E_{T} \\
(\mathrm{~kJ} / \mathrm{mol})\end{array}$ \\
\hline Blank Dye & 517 & 231.33 \\
C8(-)-2-C12(+), 3a & 530.1 & 225.61 \\
C8(-)-2-C14(+), 3b & 530.4 & 225.49 \\
C8(-)-2-C16(+), 3c & 534.4 & 223.80 \\
C8(-)-3-C12(+), 4a & 529.6 & 225.83 \\
C8(-)-3-C14(+), 4b & 530.4 & 225.49 \\
C8(-)-3-C16(+), 4c & 531.6 & 224.98 \\
\hline
\end{tabular}

micelles and no change observed with further addition of surfactants. The wavelength of maximum absorbance was used for the calculating the molar electronic transition energies $\left(E_{T}\right)$ of $\mathrm{EY}$ in each one of the zwitterionic gemini surfactants used. The $E_{T}$ values were obtained from equation 8:

$$
E_{T}=h c N_{\mathrm{A}} / \lambda_{\max }
$$

where $h$ is the Planck constant, $c$ is the vacuum light velocity. The $E_{T}$ values expressed as $\mathrm{kJ} / \mathrm{mol}$ and summarized in Table 4. The differences between $E_{T}$ values for $\mathrm{EY}$ in water and in the zwitterionic gemini surfactants revealed the variation in energy in the transfer process from water to micellar phase. Such $E_{T}$ values differences were always negative and attributed to the EY dye solubilizes better in micellar solution than in water.

\subsection{Differential scanning calorimetry}

The thermal characteristics of zwitterionic gemini surfactants were evaluated using melting temperature (Tm) measurements. The $\mathrm{Tm}$ of the zwitterionic gemini surfactants for linear spacer series C8(-)-2-C12(+), C8 (-) 
-2-C14(+) and C8 (-)-2-C16(+) were obtained at $194.44^{\circ} \mathrm{C}, 184.20^{\circ} \mathrm{C}$, and $191.90^{\circ} \mathrm{C}$ respectively and for the branched spacer series of zwitterionic gemini surfactants C8 (-)-3-C12(+), C8(-)-3-C14(+), and C8(-)-3-C16(+) were observed at $224.11^{\circ} \mathrm{C}, 197.83^{\circ} \mathrm{C}, 197.49^{\circ} \mathrm{C}$, respectively. No pronounced effect of spacer moiety and the two non identical head groups on Tm of zwitterionic gemini surfactants were observed.

\subsection{Rheology measurements}

Rheological measurement (viscosity $(\eta)$ vs. shear-rate $\left(\mathrm{S}^{-1}\right)$ ) was performed for the aqueous surfactant solutions of the zwitterionic gemini surfactants at fixed concentration(i.e.1 $\mathrm{mM})$ at $25^{\circ} \mathrm{C}$ and the results of the experiments is shown in Fig. 9. The surfactants properties were affected by its chemical structures with varying hydrophobic alkyl tail length which causes variations in micellar structures. Figure 9 shows the relation between the steady state viscosities of solutions of zwitterionic gemini surfactants with varying tail length and a shearing rate at $25^{\circ} \mathrm{C}$ independently. Figure 9 indicates that the steady state viscosities of all gemini surfactants increased with increasing shear rate, exhibiting the quality of dilatants fluids ${ }^{42}$. The steady state viscosities of all synthesized surfactants, with different tail length i.e. 12 to 16 carbon number, increases with increasing shear rate attributed to shear thickening is observed at an increased critical shear rate of $2000 \mathrm{~s}^{-1}$. As described earlier $\mathrm{cmc}$ of the zwitterionic gemini surfactants decreases with increasing tail length. At the lower cmc, all gemini surfactant solutions result in maximum linear micelles which are formed at the same concentration. These linear micelles denote the effect of steady state shearing stress. These micelles are transformed into entangled form, and consequently, viscosity increases as the shear rate increases than the critical value attributed to all aqueous solutions that show a low shear Newtonian plateau.

The effect of hydrophobic tail length on the contrast in

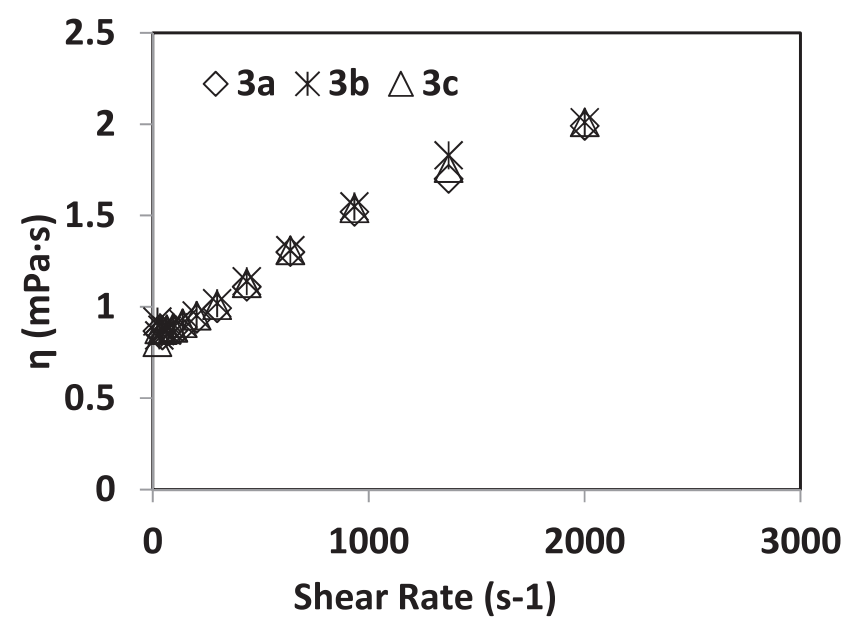

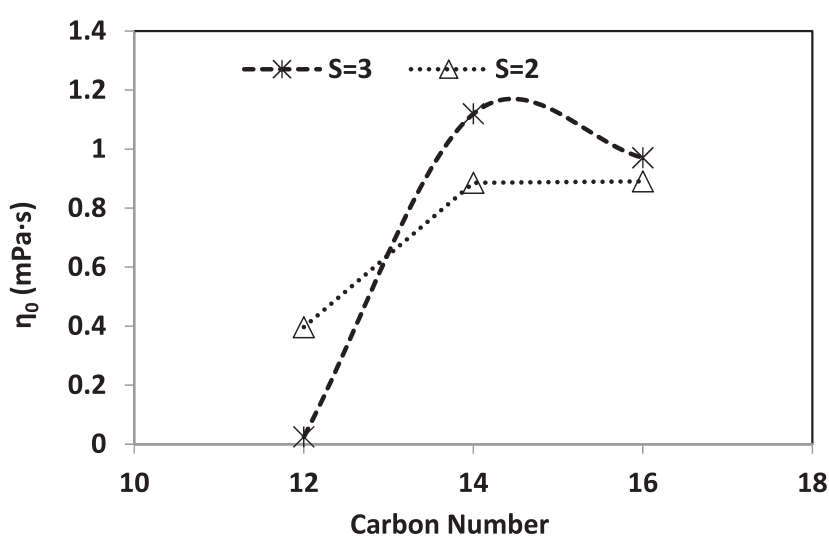

Fig. 10 Variation of zero-shear viscosity $\left(\eta_{0}\right)$ as a function of carbon number at $25^{\circ} \mathrm{C}$ of different gemini amphiphiles.

zero shear viscosity $\left(\eta_{0}\right)$, i.e., no change in viscosity at low shear rates is depicted in Fig. 10. The zero shear viscosity increases sharply with increasing tail length to 14 carbon number at cationic counterpart of gemini amphiphiles consisting of ethylene spacer $(S=2)$. The initial viscosity of the aqueous solution is 2 fold lower than that of the maximum viscosity at carbon number 14 in both the newly synthesized gemini surfactants with varying spacer $S=2$ or 3 . This increase in viscosity indicates the growth of micelles to long, entangled form of micelles ${ }^{41)}$. As depicted in Fig. 10, it is noticeable that the zero shear viscosity is minor increases in case of $\mathrm{S}=2$ and drop is observed in case of $\mathrm{S}=3$, which may be due to the distinct micellar structural interactions and connections attributed to the conversion from linear to entangled form ${ }^{43)}$.

\section{CONCLUSIONS}

An exclusively new series of zwitterionic gemini surfac-

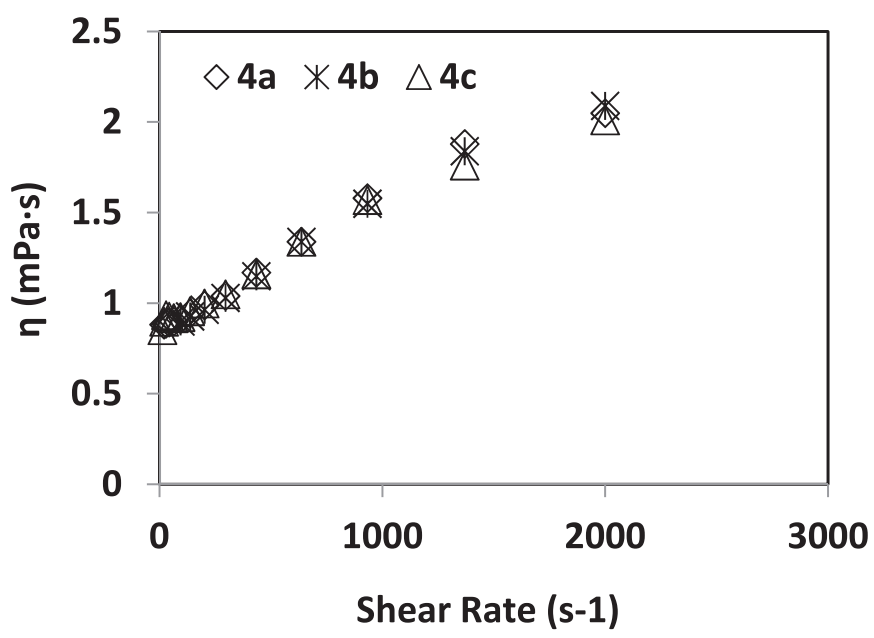

Fig. 9 Steady-shear viscosity $(\eta)$ as a function of shear rate of different gemini amphiphiles. 
tants consisting two non- identical polar heads, one negatively charged phosphodiester anion and one positively charged an ammonium cation with varying spacer have been synthesized and characterized using different spectroscopic techniques. We have noticed that both the micellization and the viscosity properties of these zwitterionic gemini surfactants are influenced by the nature of the hydrophobic alkyl chain length and influence of methyl group on spacer unit. The newly synthesized gemini surfactants had great efficiency in lowering the air/water interface, good water solubility and low cmc values. The surface parameters $\left(i . e . \gamma_{\mathrm{cmc}}, \Gamma_{\max }, \mathrm{a}_{\min }, \AA^{2}, \Pi_{\mathrm{cmc}}, \mathrm{pC}_{20}\right)$ along with the cmc values of these zwitterionic gemini surfactants considerably differ from one another depending on the type of spacer moiety and the hydrophobic alkyl chain length. Furthermore, the thermodynamic parameters were also significantly impacted by the nature of the spacer unit and hydrophobic alkyl chain length. The steady state viscosities of all gemini surfactants increased with increasing shear rate, which exhibiting the quality of dilatants fluids attributed to shear thickening. Drop in zero shear viscosities of newly synthesized surfactants of propylene spacer indicating micelles structure conversion from linear to entangled form. The interaction of EY dye and surfactants is very conspicuous and performed by dye micellization. This observation may be of practical interest for the zwitterionic gemini surfactants. All synthesized surfactants with branched tail and influence of methyl group on spacer unit are demonstrating improved performance over linear analogues in terms of micellization. Our results show that the physicochemical properties of the zwitterionic geminis can be varied by not only the change in the hydrophobic tail but also depend on the nature of spacer moiety and headgroups.

\section{ACKNOWLEDGEMENT}

The authors are thankful to University Grant Commission(UGC), Government of India for financial assistance. The authors also extend their special thanks to IIT-SAIF, Mumbai for ${ }^{1} \mathrm{H}-\mathrm{NMR},{ }^{31} \mathrm{P}-\mathrm{NMR}$, and LC-MS analysis.

\section{Supporting Information}

This material is available free of charge via the Internet at http://dx.doi.org/jos.64.10.5650/jos.ess.15299

\section{References}

1) Ansari, W. H.; Fatma, N.; Panda, M.; Kabir-ud-Din. Solubilization of polycyclic aromatic hydrocarbons by novel biodegradable cationic gemini surfactant ethane-1,2-diyl bis ( $N, N$-dimethyl- $N$-hexadecylammoniumacetoxy) dichloride and its binary mixtures with conventional surfactants. Soft Matter 9, 1478-1487 (2013).

2) Tehrani-Bagha, A. R.; Holmberg, K. Cationic EsterContaining Gemini Surfactants: Physical - Chemical Properties. Langmuir 26, 9276-9282 (2010).

3) Zhang, Q.; Cai, B.; Gang, H.; Yang, S.; Mu, B. A family of novel bio-based zwitterionic surfactants derived from oleic acid. RSC Advances 4, 38393-38396 (2014).

4) Xu, Q. Y.; Liu, Z. S.; Nakajima, M.; Ichikawa, S.; Nakamura, N.; Roy, P.; Okadome, H.; Shiina, T. Characterization of a soybean oil-based biosurfactant and evaluation of its ability to form microbubbles. Bioresour. Technol. 101, 3711-3717(2010).

5) Chu, Z. L.; Feng, Y. J. Vegetable-derived long-chain surfactants synthesized via a "Green" route. ACS Sustainable Chem. Eng. 1, 75-79(2013).

6) Zana, R.; Xia, J. in Gemini surfactants, Synthesis, Interfacial and Solution Phase-Behaviour and Applications, ed. R. Zana, J. Xia, Marcel Dekker, New York, Vol. 117, Ch. 1, pp. 9-36(2003).

7) Zana, R.; Alami, E. in Novel surfactants: Preparations, Applications, Biodegradability, ed. K. Holmberg, Marcel Dekker, New York, Vol. 117, Ch. 12, pp. 301-322 (2003).

8) Alami, E.; Lévy, H.; Zana, R.; Skoulios, A. Alkanediyl- $\alpha$, $\omega$-bis (dimethylalkylammonium bromide) surfactants. 2. Structure of the lyotropic mesophases in the presence of water. Langmuir 9, 940-944(1993).

9) Danino, D.; Talmon, Y.; Zana, R. Alkanediyl- $\alpha, \omega$-bis (dimethylalkylammonium bromide) surfactants (dimeric surfactants). 5. Aggregation and microstructure in aqueous solutions. Langmuir 11, 1448-1456 (1995).

10) Asgharian, N.; Otken, P.; Sunwoo, C.; Wade, W. H. Synthesis and performance of high efficiency cosurfactants: Model systems. Langmuir 7, 2904 (1991).

11) Asgharian, N.; Otken, P.; Sunwoo, C.; Wade, W. H. Synthesis and performance of high efficiency cosurfactants: 2. Commercial variants. J. Disp. Sci. Technol. 13, 515-525 (1992).

12) Sunwoo, C.; Wade, W. H. Optimal surfactant structures for cosurfactant-free microemulston systems I. C16 and C14 Guerbet alcohol hydrophobes. J. Disp. Sci. Technol. 13, 491-514(1992).

13) Shinoda, K.; Shibata Y. Principles for the attainment of minimum oil-water interfacial tension by surfactants: The characteristics of organized surfactant phase. Colloids Surf. 19, 185-196(1986).

14) Alami, E.; Holmberg, K. Heterogemini surfactants based on fatty acid synthesis and interfacial properties. J. Colloid Interf. Sci. 239, 230-240(2001).

15) Jaeger, D. A.; Li, B; Clark, T. Cleavable double-chain 
surfactants with one cationic and one anionic head group that form vesicles. Langmuir 12, 4314-4316 (1996).

16) Peresypkin, A. V.; Menger, F. M. Zwitterionic geminis. Coacervate formation from a single organic compound. Org. Lett. 9, 1347-1350(1999).

17) Renouf, P.; Mioskowski, C.; Lebeau, L.; Hebrault, D.; Desmurs, J. Dimeric surfactants: First synthesis of an asymmetrical gemini compound. Tetrahedron Lett. 39, 1357-1360 (1998).

18) Alami, E.; Holmberg, K.; Eastoe, J. Adsorption properties of novel gemini surfactants with nonidentical head groups. J. Colloid Interf. Sci. 247, 447-455 (2002).

19) Zhinong, G.; Shuxin, T.; Qi, Z.; Yu, Z.; Bo, L.; Yushu, G.; Li, H.; Xiaoyan, T., Synthesis and surface activity of biquaternary ammonium salt gemini surfactants with ester bond. Wuhan Univ. J. Nat. Sci. 13, 227-231 (2008).

20) Lucas, H.; Mitchell, F. Jr.; Scully, C. Cyclic phosphites of some aliphatic glycols. J. Am. Chem. Soc., 72, 5491-5497(1950).

21) Edmundson, R. S. Oxidation of cyclic phosphorochloridites. Chem. Ind. 40, 1828-1829 (1962).

22) Seredyuk, V.; Alami, E.; Nydén, M.; Holmberg, K.; Peresypkin, A.; Menger, F. Micellization and adsorption properties of novel zwitterionic surfactants. Langmuir 17, 5160-5165 (2001).

23) Menger, F. M.; Seredyuk, V. A.; Apkarian, R. P.; Wright, E. R. Colloidal assemblies of branched geminis studied by cryo-etch-HRSEM. J. Am. Chem. Soc. 124, 1240812409 (2002).

24) Kumar, A.; Alami, E.; Holmberg, K.; Seredyuk, V.; Menger, F. M. Branched zwitterionic gemini surfactants micellization and interaction with ionic surfactants. Colloids Surf. A 228, 197-207 (2003).

25) Song, L. D.; Rosen, M. J. Surface properties, micellization, and premicellar aggregation of gemini surfactants with rigid and flexible spacers. Langmuir 12, 11491153 (1996).

26) Rosen, M. J.; Mathias, J. H.; Davenport, L. Aberrant aggregation behavior in cationic gemini surfactants investigated by surface tension, interfacial tension, and fluorescence methods. Langmuir 15, 7340-7346 (1999).

27) Rosen, M. Surfactant and Interfacial Phenomenon, 2nd ed.; Wiley: New York, (1989).

28) Fisicaro, E.; Compari, C.; Biemmi, M.; Duce, E.; Peroni, M.; Barbero, N.; Viscardi, G.; Quagliotto, P. Unusual behavior of the aqueous solutions of gemini bispyridinium surfactants: apparent and partial molar enthalpies of the dimethanesulfonates. J. Phys. Chem. B 112, 12312-12317 (2008).

29) Fisicaro, E.; Compari, C.; Bacciottini, F.; Barbero, N.; Viscardi, G.; Quagliotto, P. Is the counterion responsi- ble for the unusual thermodynamic behaviour of the aqueous solutions of gemini bispyridinium surfactants? Colloids Surf. A: Physicochem. Eng. Aspects 443, 249-254 (2014).

30) Alami, E.; Beinert, G.; Marie, P.; Zana, R. Alkanediyl- $\alpha$, $\omega$ - bis (dimethylalkylammonium bromide) surfactants. 3. Behavior at the air-water interface. Langmuir 9, 1465-1467 (1993).

31) Diamant, H.; Andelmann, D. Dimeric surfactants: spacer chain confirmation and specific area at the interface. Langmuir 10, 2910-2916 (1994).

32) Diamant, H.; Andelmann, D. Dimeric surfactants: a simplified model for spacer chain. Langmuir 11, 3605-3606 (1995).

33) Tsubone, K.; Arakawa, Y.; Rosen, M. Structural effects on surface and micellar properties of alkanediyl- $\alpha$, $\omega$-bis (sodium $\mathrm{N}$-acyl- $\beta$-alaninate) gemini surfactants. J. Colloid Sci. 262, 516-524(2003).

34) Kamboj, R.; Singh, S.; Bhadani, A.; Kataria, H.; Kaur, G. Gemini imidazolium surfactants: Synthesis and their biophysiochemical study. Langmuir 28, 11969-11978 (2012).

35) Bhadani, A.; Singh, S. Synthesis and properties of thioether spacer containing gemini imidazolium surfactants. Langmuir 27, 14033-14044 (2011).

36) Villa, C.; Baldassari, S.; Martino, D.; Spinella, A.; Caponetti, E. Green synthesis, molecular characterization and associative behavior of some gemini surfactants without a spacer group. Materials 6, 1506-1519 (2013).

37) Sabate, R; Gallardo, M; de la Maza, A; Estelrich, J. A spectroscopy study of the interaction of pinacyanol with n-dodecyltrimethylammonium bromide micelles. Langmuir 17, 6433-6437 (2001).

38) Ganguly, B.; Nath, R. Study of the interaction between eosin $\mathrm{Y}$ and alkyltrimethylammonium bromide surfactants. J. Surf. Interfac. Mater. 1, 87-92 (2013).

39) Adamson, A. W. Physical Chemistry of Surfaces, 3rd ed., John Wiley and Sons, New York (1976).

40) Akbas, H.; Kartal, C. Spectrophotometric studies of anionic dye-cationic surfactant interactions in mixture of cationic and nonionic surfactants. Spectrochim. Acta A 61, 961-966 (2005).

41) Bielska, M.; Sobczynska, A; Prochaska, K. Dye-surfactant interaction in aqueous solutions. Dyes Pigm. 80, 201-205 (2009)

42) Singh, K.; Toole, Z.; McLachlan, A.; Marangoni, D. Nonaromatic hydrotropic cationic ammonium salts as a rheology modifier for an anionic/zwitterionic surfactant mixture. Langmuir 30, 3673-3680 (2014).

43) Oda, R.; Panizza, P.; Schmutz, M. Lequeux, F. Direct evidence of the shear-induced structure of wormlike micelles: Gemini surfactant 12-2-12. Langmuir 13, 6407-6412(1997). 